\title{
Inhibitory Gating of Vibrissal Inputs in the Brainstem
}

\author{
Takahiro Furuta, ${ }^{1}$ Elena Timofeeva, ${ }^{2}$ Kouichi Nakamura, ${ }^{1,3}$ Keiko Okamoto-Furuta, ${ }^{1}$ Masaya Togo, ${ }^{1}$ Takeshi Kaneko,,${ }^{1,3}$ \\ and Martin Deschênes ${ }^{2}$ \\ ${ }^{1}$ Department of Morphological Brain Science, Graduate School of Medicine, Kyoto University, Kyoto 606-8501, Japan, ${ }^{2}$ Centre de Recherche Université \\ Laval Robert-Giffard, Québec City, Québec, Canada G1J 2G3, and ${ }^{3}$ Core Research for Evolution Science and Technology, Japan Science and Technology \\ Agency, Kawaguchi 332-0012, Japan
}

Trigeminal sensory nuclei are the first processing stage in the vibrissal system of rodents. They feature separate populations of thalamic projecting cells and a rich network of intersubnuclear connections, so that what is conveyed to the cortex by each of the ascending pathways of vibrissal information depends on local transactions that occur in the brainstem. In the present study, we examined the nature of these intersubnuclear connections by combining electrolytic lesions with electrophysiological recordings, retrograde labeling with in situ hybridization, and anterograde labeling with immunoelectron microscopy. Together, these different approaches provide conclusive evidence that the principal trigeminal nucleus receives inhibitory GABAergic projections from the caudal sector of the interpolaris subnucleus, and excitatory glutamatergic projections from the caudalis subnucleus. These results raise the possibility that, by controlling the activity of intersubnuclear projecting cells, brain regions that project to the spinal trigeminal nuclei may take an active part in selecting the type of vibrissal information that is conveyed through the lemniscal pathway.

Key words: vibrissa; barrels; sensory gating; trigeminothalamic pathways; whisking; GAD

\section{Introduction}

The vibrissal system of rodents comprises several ascending pathways of information processing (for review, see Kleinfeld et al., 2006). Each pathway arises from a specific population of brainstem trigeminal neurons, transits through a specific thalamic region, and has its own areal and laminar distribution in the neocortex. In the brainstem, these parallel streams of information processing are not totally isolated from each other, in that each trigeminal subnucleus that gives rise to an ascending pathway receives projections from the other subnuclei (Jacquin et al., 1990b; Timofeeva et al., 2004). This is the case, for instance, of the principal trigeminal nucleus $(\mathrm{PrV})$ that gives rise to the lemniscal pathway, and receives profuse projections from the interpolaris $(\mathrm{SpVi})$ and caudalis subnuclei $(\mathrm{SpVc})$. Lesion of these intersubnuclear projections significantly reduces receptive field size in the $\mathrm{PrV}$, thalamus, and cortex (i.e., the number of vibrissae to which a cell responds) (Timofeeva et al., 2004; Kwegyir-Afful et al., 2005). As another effect of the lesion, inhibition that follows whisker-evoked excitation in the PrV is also markedly reduced (Timofeeva et al., 2004) (see supplemental Fig. 1, available at www.jneurosci.org as supplemental material), which suggests that some of the intersubnuclear connections might exert an inhibitory function. Yet, none of the interpolaris or caudalis neu-

Received 0ct. 11, 2007; revised Dec. 7, 2007; accepted Dec. 31, 2007.

This work was supported by the Canadian Institute of Health Research Grant MT-5877 (M.D.) and the Ministry of Education, Science, Sports, and Culture of Japan Grants 18019017 and 18700342 (T.F.). We thank Dr. H. Bokor for helpful advice on EM methods. We also acknowledge Drs. F. Erdelyi and G. Szabo (Institute of Experimental Medicine, Budapest, Hungary) for the generous gift of GAD-GFP mice.

Correspondence should be addressed to Dr. Martin Deschênes, Centre de Recherche Université Laval RobertGiffard, 2601 de la Canardière, Québec City, Québec, Canada G1J 2G3. E-mail: martin.deschenes@crulrg.ulaval.ca. DOI:10.1523/JNEUROSCI.4627-07.2008

Copyright $\odot 2008$ Society for Neuroscience $\quad$ 0270-6474/08/281789-09\$15.00/0 rons retrogradely labeled from the $\operatorname{PrV}$ were reported to be immunoreactive for GABA or glutamic acid decarboxylase (GAD) (Haring et al., 1990). This is somehow intriguing because singlecell labeling studies already showed that the SpVi projection to the PrV arises principally from small-sized local circuit cells (Jacquin et al., 1989a), and in situ hybridization of the GAD67 mRNA has revealed a large number of small-sized GABAergic cells in the SpVi (Furuta et al., 2006). Moreover, electron microscopic studies already documented a rich network of synaptic contacts with numerous axodendritic and axoaxonic GABAergic synapses in sensory trigeminal nuclei (Ide and Killackey, 1985; Bae et al., 2000, 2005). Here, we re-examined the nature of these connections by combining electrolytic lesion with electrophysiological recordings, retrograde labeling with in situ hybridization, and anterograde labeling with electron microscopy. Together, these different approaches provide direct evidence for the existence of intersubnuclear GABAergic projections that significantly suppress the relay of vibrissal information through the PrV. On the basis of this result, it is proposed that intersubnuclear inhibitory connections might take part in a gating mechanism that can be controlled by central pathways.

\section{Materials and Methods}

Animal preparation and recordings. Experiments were performed in 31 male rats (Sprague Dawley, 250-300 g) and five transgenic mice in accordance with federally prescribed animal care and use guidelines. The Ethical Committee for Animal Use in Research (Laval University) and the Institute of Laboratory Animals, Graduate School of Medicine, Kyoto University approved all experimental protocols. Transgenic mice expressed the green fluorescent protein (GFP) under the control of the GAD promoter (GAD-GFP mice).

Electrophysiological experiments were conducted under ketamine ( 75 $\mathrm{mg} / \mathrm{kg}) / \mathrm{xylazine}(5 \mathrm{mg} / \mathrm{kg})$ anesthesia. The left facial nerve was cut, and 
the animal was placed in a stereotaxic apparatus. The animal breathed freely, and body temperature was maintained at $37.5^{\circ} \mathrm{C}$ with a heating pad controlled thermostatically. Throughout the experiment, a deep level of anesthesia was maintained (stage III-3) (Friedberg et al., 1999) by additional doses of anesthetics given at $1 \mathrm{~h}$ interval (ketamine $20 \mathrm{mg} / \mathrm{kg}$ plus xylazine $0.3 \mathrm{mg} / \mathrm{kg}$, i.m.).

Single PrV units were recorded with glass micropipettes $(1 \mu \mathrm{m})$ filled with a solution of potassium acetate $(0.5 \mathrm{~m})$. Signals were amplified, bandpass filtered ( $150 \mathrm{~Hz}$ to $3 \mathrm{kHz}$ ), sampled at $10 \mathrm{kHz}$, and stored on hard disk for off-line analysis. Data analysis was performed with the Neuroexplorer (Plexon, Dallas, TX), Excel (Microsoft, Redmond, WA), and StatView (SAS Institute, Cary, NC) softwares.

Whisker stimulation. Vibrissae were cut $\sim 2.5 \mathrm{~cm}$ from the skin, and the whisker that most effectively drove a cell [the principal whisker (PW)] was identified by manual deflection under a dissecting microscope. Then, the PW was deflected in the ventrocaudal direction with a $50 \mathrm{~ms}$ air jet generated by a Picospitzer (40 psi; interstimulus interval, $1 \mathrm{~s}$; General Valve, Brooshire, TX) connected to a glass capillary (tip diameter, $\sim 500$ $\mu \mathrm{m})$. The tip of the capillary was positioned at a distance of $4-5 \mathrm{~cm}$ of the vibrissae, and the air jet was directed away from the rat's face to avoid as much as possible stimulating other orofacial afferents. This created a cone-shaped air puff that deflected six to seven whiskers about the PW. The delay between the command voltage and the actual motion of vibrissae was measured by placing a piezoelectric film (Measurement Specialties, Fairfield, NJ) at the same distance from the tip of the capillary. This delay was subtracted from the recordings to build poststimulus time histograms (PSTHs; bin width: $1 \mathrm{~ms}$ ) of sensory-evoked responses.

The main goal of the present study was to determine whether intersubnuclear projections from the spinal complex could inhibit vibrissal responses in PrV. To address this question, we built a single-whisker flutter stimulator that consisted of a brass tube (diameter, $4 \mathrm{~mm}$ ) to which a pipette tip (Eppendorf, Hamburg, Germany; $200 \mu \mathrm{l}$ ) was fixed with acrylic cement (supplemental Fig. 2, available at www.jneurosci.org as supplemental material). The tip of the pipette was trimmed at $\sim 1 \mathrm{~mm}$, and an opening ( $\sim 3 \mathrm{~mm}$ in diameter $)$ was made on the side of the plastic pipette $\sim 2.5 \mathrm{~cm}$ from the tip. The brass tube was connected to a small compressor powered by a variable voltage source that allowed regulation of the airflow. Once a PW has been identified, it was inserted into the lumen of the plastic pipette. The pipette gently pressed against the pad to completely mask the PW, and prevent its deflection when an air jet was applied to the surrounding whiskers. When air flew through the flutter stimulator, the turbulent stream at the outlet induced vibration of the masked whisker, thus inducing sustained discharges in the associated PrV cells. As observed under a dissecting microscope, the outflow of air did not disturb the adjacent whiskers.

Once a PW was identified, a PSTH was built by collecting 20 responses to the air jet stimulus. Then, the PW was inserted into the lumen of the flutter stimulator, and a second PSTH (20 responses) was built to detect the effect of surround whisker deflection. Finally, the flutter stimulus was turned on, and a third PSTH was built by collecting $80-100$ responses to air-jet stimulation of the adjacent whiskers. Collecting such a large number of responses ensures that background activity (counts per bin) was large enough to assess a statistically significant amount of inhibition. We tested for the presence of inhibitory responses by comparing firing rates within a $50 \mathrm{~ms}$ time window after stimulus onset to prestimulus firing rates estimated over a $50 \mathrm{~ms}$ period ( $\alpha=0.025$; one-tailed $t$ test). The magnitude of inhibition was rated as the percentage difference in the mean number of counts per bin during the prestimulus and poststimulus time windows.

Brainstem lesion. A unilateral electrolytic lesion of the SpVi was made with a tungsten electrode (shaft diameter, $200 \mu \mathrm{m}$; tip diameter, $50 \mu \mathrm{m}$; deinsulated over $1 \mathrm{~mm}$ ). The electrode was lowered through the cerebellum (12 mm behind the bregma, $3.2 \mathrm{~mm}$ lateral to the midline (Paxinos and Watson 1998) until the floor of the brainstem was reached. Then the electrode was retracted in steps of $500 \mu \mathrm{m}$, and direct current ( $3 \mathrm{~mA}, 4 \mathrm{~s})$ was applied at four depths. At the end of the recording sessions, animals were perfused under deep anesthesia with saline followed by a solution of $4 \%$ paraformaldehyde in PBS $(0.1 \mathrm{M}, \mathrm{pH}$ 7.4). The brainstem was coro- nally cut at $70 \mu \mathrm{m}$, and the extent of the lesion was visualized after processing sections for cytochrome oxidase histochemistry.

Tract tracing experiments. Tracer injections were made in 10 rats and 5 GAD-GFP mice under ketamine/xylazine anesthesia. Retrograde labeling in rats was performed by pressure injection into the $\operatorname{PrV}$ of $0.2 \mu \mathrm{l}$ of $1 \%(w / v)$ Alexa 555-conjugated cholera toxin B subunit (A555-CTB; Invitrogen, Eugene, OR) dissolved in PBS (0.1 M, pH 7.4). In mice, Fluorogold (FG) was injected into the PrV by iontophoresis (2\% FG in $0.1 \mathrm{M}$ cacodylate buffer, $\mathrm{pH} 7$; positive current pulses of $2 \mu \mathrm{A}, 2 \mathrm{~s}$ duty cycle). The anterograde labeling of intersubnuclear projections was achieved by pressure injection in the SpVi of $0.5 \mu \mathrm{l}$ of GFP-expressing recombinant Sindbis virus $\left(2 \times 10^{9}\right.$ infectious $\left.\mathrm{U} / \mathrm{ml}\right)$ (Furuta et al., 2001).

After survival periods of $18-48 \mathrm{~h}$, the animals were deeply anesthetized and perfused transcardially with $200 \mathrm{ml}$ of PBS followed by $300 \mathrm{ml}$ of $4 \%(\mathrm{w} / \mathrm{v})$ formaldehyde in $0.1 \mathrm{~m}$ phosphate buffer, $\mathrm{pH} 7.4$, or $4 \%(\mathrm{w} / \mathrm{v})$ formaldehyde and $0.5 \%(\mathrm{w} / \mathrm{v})$ glutaraldehyde in $0.1 \mathrm{~m}$ phosphate buffer for retrograde and anterograde tracing, respectively.

In situ hybridization. After fixation, brains were cryoprotected with $30 \%(\mathrm{w} / \mathrm{w})$ sucrose in PBS and cut horizontally at $50 \mu \mathrm{m}$ on a freezing microtome. Complementary DNA fragments corresponding to regions of the GAD67 (a marker of GABAergic neurons) cDNA (nucleotides 276-894; GenBank accession number NM_008077), the vesicular inhibitory amino acid transporter (VIAAT; a marker of GABAergic and glycinergic neurons) cDNA (866-1817; NM-009508), the vesicular glutamate transporter type 1 (VGluT1; a marker of excitatory neurons) cDNA (855-1788; XM_133432.2), and the vesicular glutamate transporter type 2 (VGluT2, a marker of excitatory neurons) cDNA (848-2044; NM_080853.2) were cloned into vector pBluescript II SK(+) (Stratagene, La Jolla, CA). With the linearized plasmid as template, sense and antisense single-strand RNA probes were synthesized with a digoxigenin labeling kit (Roche Diagnostics, Basel, Switzerland). The procedure for nonradioactive in situ hybridization has been described previously (Liang et al., 2000). Briefly, free-floating sections were washed in phosphate buffer for $5 \mathrm{~min}$ and then acetylated in freshly prepared $0.25 \%$ $(\mathrm{v} / \mathrm{v})$ acetic anhydride in $0.1 \mathrm{~m}$ triethanolamine for $10 \mathrm{~min}$ by vigorous shaking. After a rinse with $30 \mathrm{~mm} \mathrm{NaCl}$ and $30 \mathrm{~mm}$ sodium citrate $(2 \times$ SSC), sections were hybridized with $1.0 \mathrm{~g} / \mathrm{ml}$ digoxigenin-labeled sense or antisense RNA probes for GAD67, VIAAT, VGluT1, and VGluT2 in a mixture of $50 \%(\mathrm{v} / \mathrm{v})$ formamide, $5 \times$ SSC, $2 \%$ blocking reagent (Roche Diagnostics), $0.1 \% \mathrm{~N}$-lauroylsarcosine (NLS), and $0.1 \%$ SDS for $20 \mathrm{~h}$ at $70^{\circ} \mathrm{C}$. After washing twice in $50 \%$ formamide, $2 \times$ SSC, and $0.1 \%$ NLS for $20 \mathrm{~min}$ at $70^{\circ} \mathrm{C}$, sections were incubated with $20 \mathrm{~g} / \mathrm{ml} \mathrm{RNase}$ A for $30 \mathrm{~min}$ at $37^{\circ} \mathrm{C}$, washed twice for $20 \mathrm{~min}$ at $37^{\circ} \mathrm{C}$ in $2 \times \mathrm{SSC}$ and $0.1 \% \mathrm{NLS}$, and then in $0.2 \times$ SSC and $0.1 \%$ NLS. Subsequently, sections were incubated with 1:3000-diluted peroxidase-conjugated sheep anti-digoxigenin antibody Fab fragment (Roche Diagnostics) and the signals were amplified with a biotinyl tyramide reagent (Adams, 1992). Then, sections were incubated with Alexa 488-conjugated streptavidin ( $10 \mu \mathrm{g} / \mu \mathrm{l}$; Invitrogen) in PBS containing $0.3 \%$ Triton X-100 for $1 \mathrm{~h}$. Hybridization with the sense probe did not produce any signals. Some sections were stained with cresyl violet or cytochrome oxidase histochemistry.

Cell count. Horizontal sections midway through the dorsoventral extent of the SpVi and SpVc were used for counting tracer- and mRNAspositive neurons. The number of retrogradely labeled cells in sections processed for in situ hybridization was estimated under confocal microscopy with a $40 \times$ objective (Pascal; Zeiss, Oberkochen, Germany). Approximately 20 adjacent fields were scanned in a grid-like manner across the entire SpVi and SpVc in each section. For each field a stack of 10 optical slices was acquired, and counts were made from the stacked images.

Electron microscopy. Brains that received virus injection were cut into 50 - $\mu$ m-thick horizontal sections on a vibratome (Microslicer DTK1000; Dosaka, Kyoto, Japan). Sections were incubated in PBS containing $20 \%$ normal donkey serum and $0.2 \%$ Photo-Flo and then incubated overnight with anti-GFP guinea pig antibody $(0.05 \mu \mathrm{g} / \mu \mathrm{l})$ in PBS containing $2 \%$ normal donkey serum and $0.2 \%$ Photo-Flo at $4^{\circ} \mathrm{C}$. After washing with PBS, sections were incubated overnight with 1:1000 diluted gold-conjugated anti-guinea pig IgG goat antibody (Nanoprobes, Yaphank, NY) in PBS containing $2 \%$ normal donkey serum at $4^{\circ} \mathrm{C}$, post- 

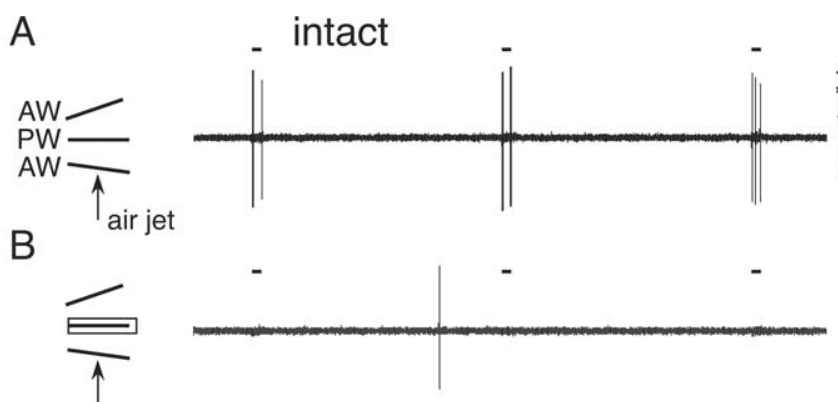

C
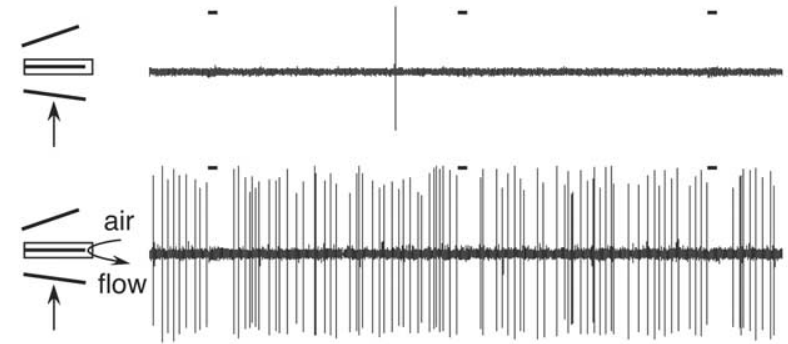

D
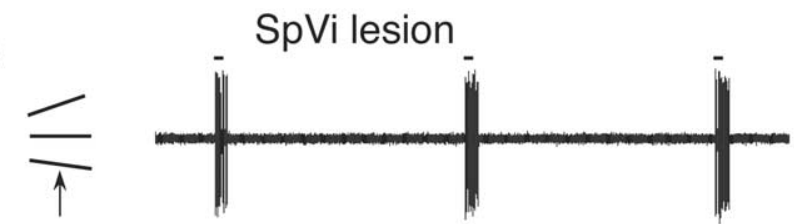

E
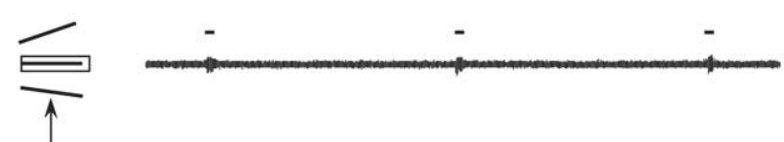

F

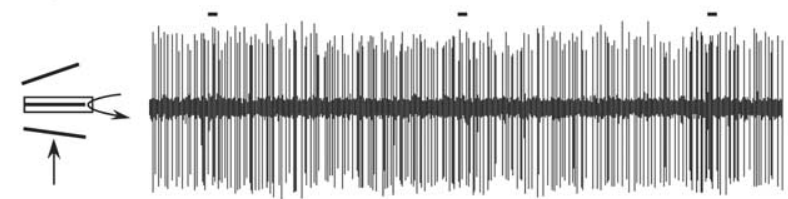

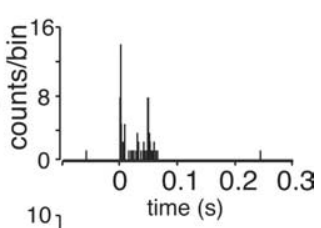
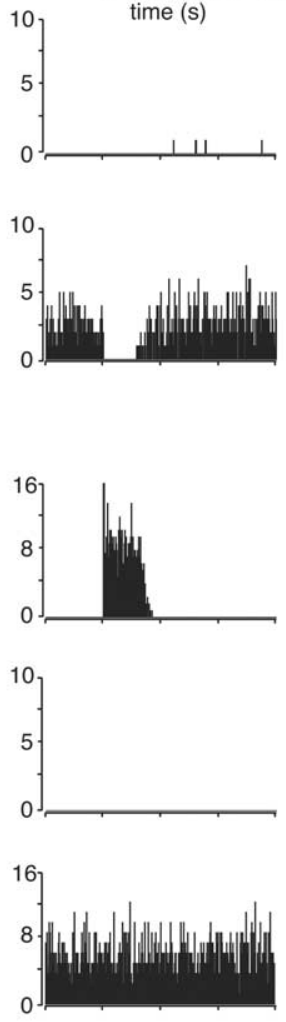
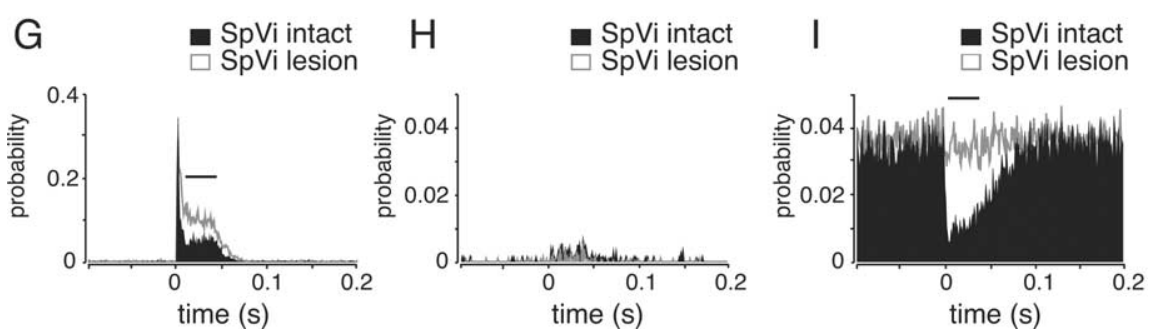

Figure 1. Inhibition mediated by intersubnuclear projections in the PrV. Traces $\mathbf{A}-\mathbf{C}$ and the associated right-hand PSTHs show the responses of a PrV neuron to deflection of vibrissa $\mathrm{C} 1$ in a normal rat. $A$, Response to an air jet when vibrissa $\mathrm{C} 1$ was unmasked. $\boldsymbol{B}$, Response to air jet deflection of the surrounding whiskers when vibrissa $C 1$ was masked within the lumen of the flutter stimulator. $C$, Response to the same air jet when vibrissa C 1 was masked, and the cell was activated by airflow through the flutter stimulator. Traces $\boldsymbol{D}-\boldsymbol{F}$ and associated right-hand PSTHs show the responses of a PrV neuron to deflection of vibrissa C 4 in an SpVi-lesioned rat. $\boldsymbol{D}$, Response to an air jet when vibrissa (4 was unmasked. $\boldsymbol{E}$, Response to air jet deflection of the surrounding whiskers when vibrissa ( 4 was masked within the lumen of the flutter stimulator. $F$, Response to the same air jet when vibrissa C4 was masked, and the cell was activated by airflow through the flutter stimulator. Note that surround whisker-induced inhibition in intact rat $(\boldsymbol{C})$ was absent in lesioned rat $(\boldsymbol{F}) . \mathbf{G}-\mathbf{I}$, Population PSTHs show the average probability of response to the air jet in normal ( $n=46$ cells) and lesioned rats ( $n=52$ cells). $\boldsymbol{G}$, Responses to an air jet when the PW was unmasked. $\boldsymbol{H}$, Response to air jet deflection of the surrounding whiskers when the PW was masked. I, Responses to an air jet when the PW was masked, and cells were activated by airflow through the flutter stimulator. Horizontal bars in $\mathbf{G}$ and $\mathbf{I}$ indicate periods (duration, $50 \mathrm{~ms}$ ) during which a significant difference in response probability was computed.

fixed in 2\% glutaraldehyde in PBS, then silver intensified with HQ Silver kit (Nanoprobes, Stony Brook, NY). All sections were treated with OsO4 ( $1 \%$ for $1 \mathrm{~min}$, and $0.5 \%$ for $20 \mathrm{~min}$ at $4^{\circ} \mathrm{C}$ ) in phosphate buffer, dehydrated in ethanol and propylene oxide, and embedded in Durcupan (Fluka, Buchs, Switzerland). During dehydration, sections were treated with $1 \%$ uranyl acetate in $70 \%$ ethanol for $40 \mathrm{~min}$. Ultrathin sections were cut with an ultramicrotome (Reichert-Nissei Ultracut S; Leica, Hei- derberg, Germany), and sections were mounted on nickel grids. Postembedding GABA immunostaining was performed according to the protocol of Somogyi et al. (1985). Ultrathin sections were observed with an electron microscope (H-7100; Hitachi, Tokyo, Japan).

\section{Results \\ Electrophysiological evidence for intersubnuclear inhibition}

Timofeeva et al. (2004) provided the first piece of evidence for the existence of intersubnuclear inhibitory connections in the brainstem trigeminal complex. As shown in supplemental Figure 1 (available at www. jneurosci.org as supplemental material), which duplicates part of those results, a marked reduction in the magnitude of vibrissal responses was observed in the PrV after lesion of the SpVi. In normal rats, population PSTH in response to an air jet exhibited a transient peak of excitation at stimulus onset, which was followed by an abrupt decline during the stimulus plateau (supplemental Fig. 1A, available at www. jneurosci.org as supplemental material). The early peak of excitation was still prominent in SpVi-lesioned rats, but the decline of sustained discharges was markedly attenuated (supplemental Fig. $1 B$, available at www.jneurosci.org as supplemental material). This result suggested that the SpVi lesion might have severed intersubnuclear connections that exert an inhibitory action in the PrV.

To further address this question, we used a deeply anesthetized preparation in which most of the PrV cells responded to a single whisker. Approximately $15 \%$ of the recorded cells were equally well driven by the motion of several whiskers, but these units were not considered in the present study. At rest, monowhisker PrV units displayed low spontaneous activity $(<1 \mathrm{~Hz})$, and responded briskly to an air jet stimulus (Fig. 1A). After the effective whisker was masked within the lumen of the flutter stimulator, air jet deflection of the surrounding whiskers did not evoke any response (Fig. 1B). However, if PrV cells were induced to fire by airflow through the flutter stimulator, then surround whisker deflection produced a marked suppression of background discharges (Fig. 1C). When the same stimulation protocol was applied in SpVi-lesioned rats (lesion shown in supplemental Fig. 3, available at www.jneurosci.org as supplemental material), no inhibition was noticed (Fig. 1D-F). Population PSTHs of Figure $1 G-I$ summarize results obtained in intact rats ( $n=46$ cells) and in SpVi-lesioned rats ( $n=52$ cells).

Statistical analysis of the responses of individual PrV units did not reveal any significant difference in the magnitude of the early responses $(0-5 \mathrm{~ms}$ after stimulus onset) between intact and 
SpVi-lesioned rats when the PW was not masked (paired $t$ test, $p=0.42$ ). However, during the plateau response (6-50 $\mathrm{ms}$ after stimulus onset), the probability of response in lesioned rats was significantly higher than in intact animals (paired $t$ test, $p<0.0001$ )

When PrV units were induced to fire by vibrating the masked PW with the flutter stimulator, air-jet stimulation of the surrounding whiskers in intact rats significantly reduced the probability of discharges during the first $50 \mathrm{~ms}$ after stimulus onset compared with SpVilesioned rats (paired $t$ test, $p<0.0001$ ). Comparison of the firing rates of each neuron before and after air jet stimulation revealed that $89 \%$ of the neurons in intact rats $(n=41$ cells $)$ significantly decreased their activity within a time window of 50 ms after the air-jet (unpaired $t$ test, $p<$ $0.05)$, whereas the remaining cells $(n=5)$ did not. In contrast, $81 \%$ of the units in SpVi-lesioned rats ( $n=42$ cells) did not reduce their activity during the air jet, whereas 10 neurons (19\%) did (unpaired $t$ test, $p<0.05$ ).

In sum, comparison of the electrophysiological results in normal and lesioned rats reveals that the spinal trigeminal nuclei can exert a strong inhibitory action on the relay of vibrissal inputs in PrV. It remained to determine whether response suppression was mediated by intersubnuclear inhibitory connections, or by excitatory intersubnuclear connections that activated local circuit inhibitory cells within the PrV.

\section{Distribution of glutamatergic and \\ GABAergic neurons in the trigeminal nuclei}

Single-cell labeling studies already disclosed two categories of vibrissa-sensitive units in brainstem trigeminal nuclei: projection cells that innervate the thalamus, cerebellum, or superior colliculus, and local circuit cells that project to the other subnuclei of the trigeminal column (Jacquin et al., 1989a,b). Although the application of glutamate receptor antagonists in vivo or in vitro, and immunolabeling for the vesicular glutamate transporters have provided direct evidence that thalamic-projecting neurons use glutamate as a neurotransmitter (for review, see Salt, 2002; Lavallée et al., 2005), the neurotransmitter(s) used by intersubnuclear projecting cells remain undetermined. To further characterize these different neuronal populations we used in situ hybridization for glutamate- and GABA-related specific transcripts. In situ hybridization for VGluT1 labeled large-sized neurons throughout the $\mathrm{SpVi}$, a dense population of small-sized cells in the PrV, and a smaller population of large cells in the rostromedial part of the PrV and in the neighboring infratrigeminal nucleus (Fig. 2A). The oralis subnucleus (SpVo) and SpVc con-
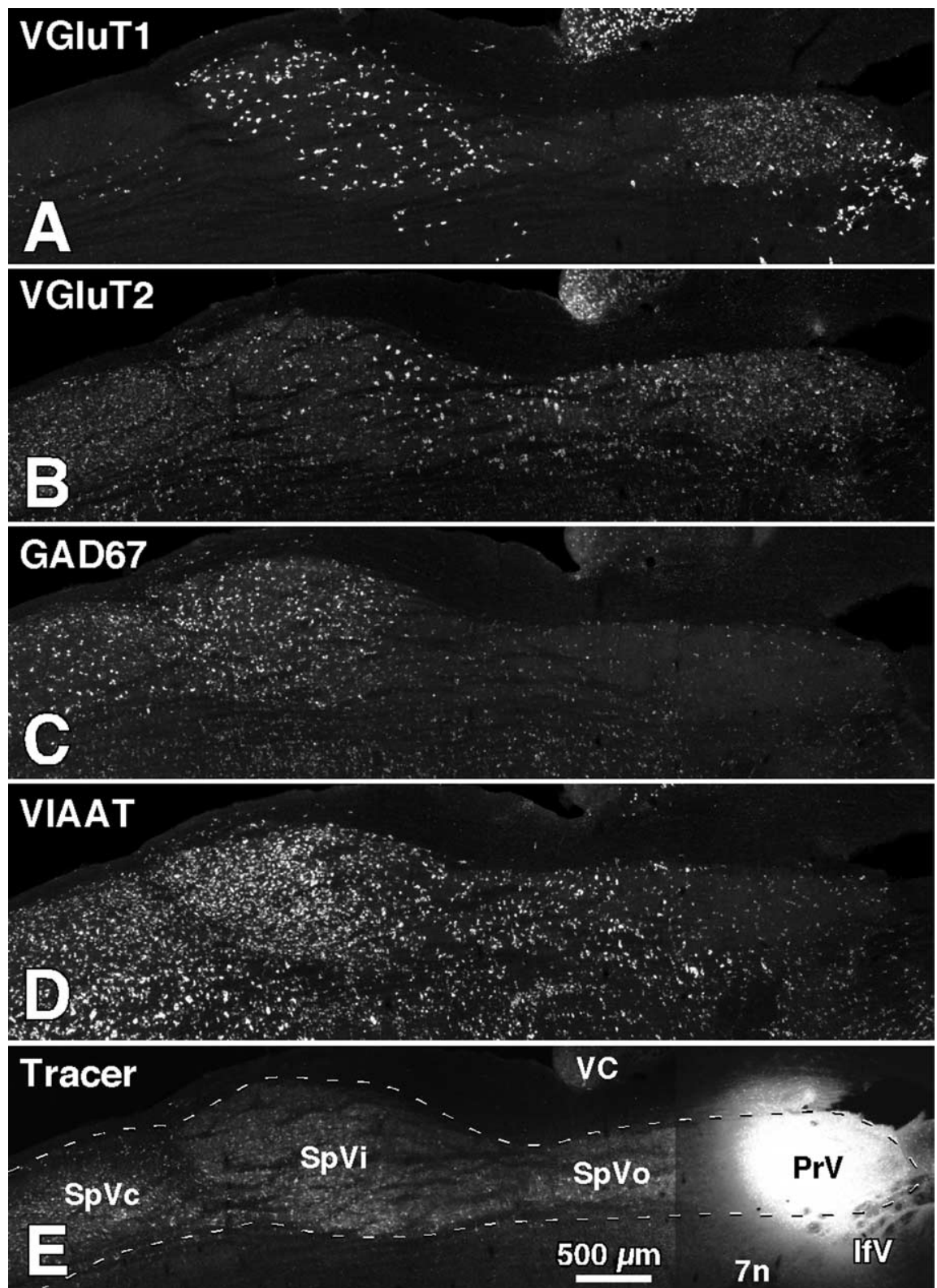

Figure 2. Distribution of glutamatergic and GABAergic cells in brainstem trigeminal nuclei. $A-D$, In situ hybridization of VGluT1 (A), VGluT2 (B), GAD67 (C), and VIAAT (D) transcripts in horizontal sections of the brainstem. VGluT1- and VgluT2-positive cells are glutamatergic (excitatory); GAD67-positive cells are GABAergic (inhibitory); VIAAT-positive cells are either GABAergic or glycinergic (inhibitory). $\boldsymbol{E}$, Injection of cholera toxin B subunit in the PrV led to the retrograde labeling of cells throughout the trigeminal column, with the densest concentrations in the caudal half of the SpVi and in the SpVc. Labeling in the SpVo mostly consisted of passing intersubnuclear axons. Horizontal sections of the brainstem are similarly aligned, so that the labeling of nuclear divisions in $\mathrm{E}$ also applies to the top. 7n, Facial nerve tract; ifV, infratrigeminal nucleus; VC, ventral cochlear nucleus.

tained the lowest density of cells expressing this transcript. A dense population of small-sized PrV cells expressed VGluT2, which was also strongly expressed by large-sized neurons in the SpVo and in the rostral sector of the SpVi. The density of VGluT2-positive cells decreased in the caudal part of the $\mathrm{SpVi}$, and was moderate in the SpVc (Fig. 2B). In situ hybridization for the GAD and VIAAT mRNAs labeled a high density of small cells in the caudal sector of the SpVi and in the SpVc, and a moderate number of cells in the SpVo. The lowest expression of both GABA-related transcripts was observed in the $\operatorname{PrV}$ (Fig. 2C,D). Altogether, these results show that the different subnuclei that give rise to the ascending vibrissal pathways contain different subtypes of glutamatergic cells and different density of GABAergic neurons. 


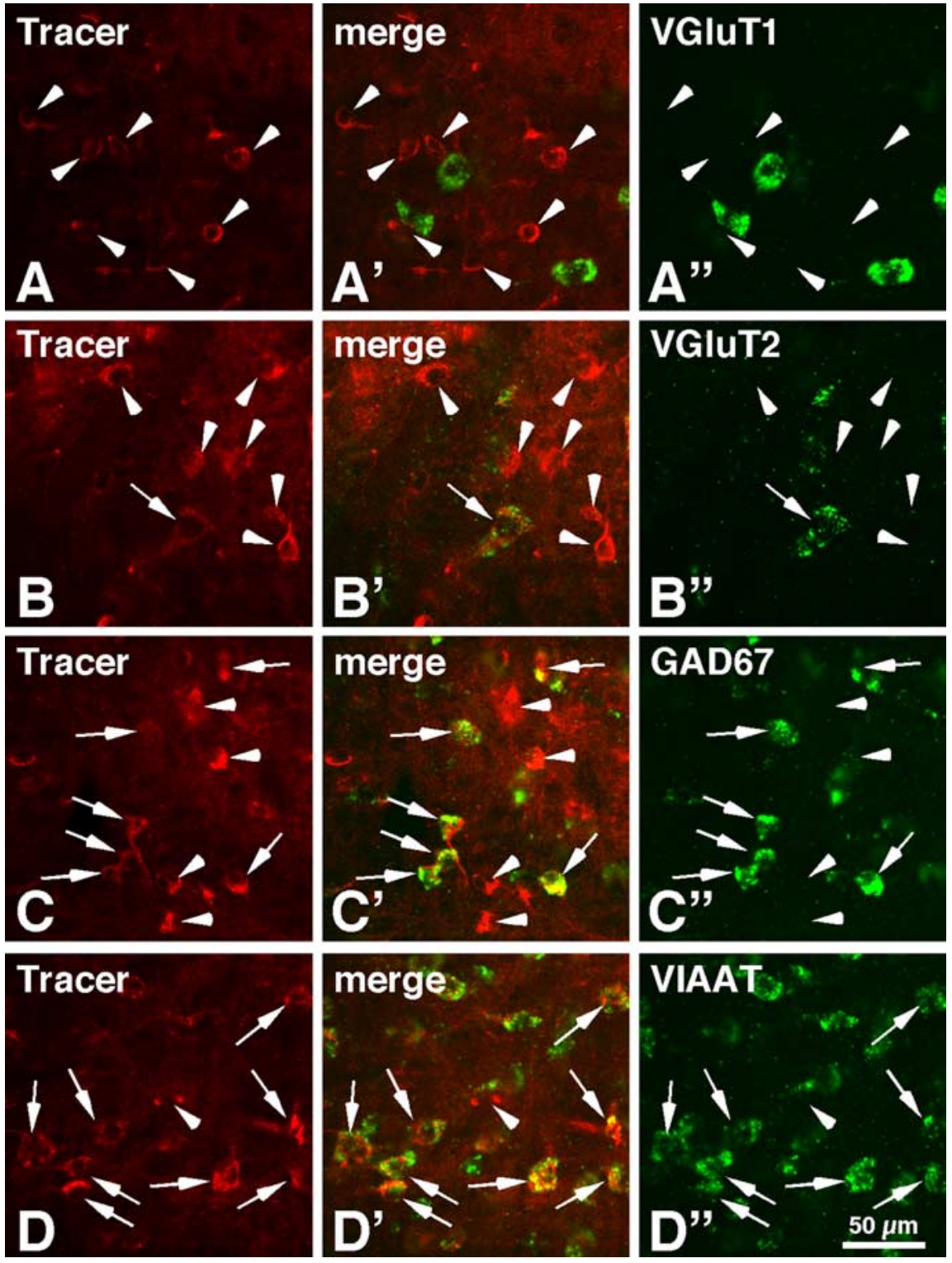

Figure 3. Expression of glutamate- and GABA-related specific transcripts in interpolaris cells retrogradely labeled after (TB injection in the PrV. $\boldsymbol{A}-\boldsymbol{D}^{\prime \prime}$ provide representative examples of singly labeled (arrowheads) and doubly labeled (arrows) neurons.

\section{Origin and neurochemical content of intersubnuclear projections to the $\mathrm{PrV}$}

As reported previously by Jacquin et al. (1990b) in rat and Ikeda et al. (1984) in cat, tracer injection in the PrV led to the retrograde labeling of a large number of cells throughout the ipsilateral trigeminal column. The vast majority of these cells displayed smallsized somata $(<20 \mu \mathrm{m})$, and their density was particularly high in the caudal sector of the SpVi and in the SpVc (Fig. 2E). When retrograde labeling was combined with in situ hybridization, none of the retrogradely labeled cells in the caudal sector of the SpVi expressed VGluT1 mRNA (0 of 920), and a few expressed VGluT2 mRNA (12\%; 129 of 1036), whereas 57\% (458 of 799) expressed the GAD67 transcript, and 86\% (694 of 808) the VIAAT transcript (Fig. 3).

In contrast, $\mathrm{SpVc}$ projection to the $\mathrm{PrV}$ consisted of relatively few cells expressing the VGluT1 (7\%; 42 of 568), GAD67 (11\%; 67 of 604$)$, or VIAAT (16\%; 91 of 575) transcripts, but a large proportion expressed VGluT2 (77\%; 396 of 512) (Fig. 4). Thus, these results provide direct evidence that intersubnuclear projec- tions to the PrV arise from different populations of GABAergic and glutamatergic neurons that are principally located in the caudal sector of the SpVi and in the SpVc, respectively.

Intersubnuclear GABAergic projections in GAD-GFP mice

In accord with the results of in situ hybridization in rats, the PrV in GAD-GFP mice contained very few GFP-positive cells, whereas the SpVi contained the most (supplemental Fig. $4 A, B$, available at www. jneurosci.org as supplemental material). Fluorogold injection into the PrV of three GAD-GFP mice also revealed a number of doubly labeled cells in the SpVi (supplemental Fig. 4C,D, available at www. jneurosci.org as supplemental material), which confirms that, just like in rats, the $\mathrm{SpVi}$ in mice is at the origin of a significant GABAergic projection to the PrV.

\section{Electron microscopy}

The ultrastructure of the synaptic contacts established by interpolaris axons in the PrV was studied in six rats by examining 101 vesicle-containing terminals that had been anterogradely labeled with a GFPexpressing recombinant Sindbis virus injected into the caudal sector of the $\mathrm{SpVi}$ (Fig. 5A,B). Seventy-six of these terminals exhibited GABA immunoreactivity, among which 43 made symmetric $(n=40)$ or asymmetric $(n=3)$ synaptic contacts with dendrites (Fig. 5C). Two of the 76 terminals established axoaxonic contacts with GFP-negative large terminals that contained many mitochondria and made asymmetric synapses with dendrites.

\section{Discussion}

Trigeminal sensory nuclei are the first processing stage in the vibrissal system of rodents. They feature separate populations of thalamic projecting cells, and a rich network of intersubnuclear connections, so that what is conveyed to the cortex by each of the ascending pathways depends on local transactions that occur in the brainstem. The present study provides direct evidence that GABAergic cells in the SpVi project to the PrV, and that this projection can suppress the relay of vibrissal messages in the lemniscal pathway. Thus, this result raises the possibility that, by controlling the activity of intersubnuclear projecting cells, brain regions that project to the SpVi may take an active part in selecting the type of vibrissal information that is conveyed through the lemniscal pathway.

\section{Intersubnuclear inhibitory projections}

In situ hybridization of GABA-related transcripts in rats and GFP expression under the GAD promoter in transgenic mice indicate that the PrV contains few GABAergic neurons, whereas the caudal part of the SpVi and the SpVc contain the most. The expression of VIAAT is particularly telling in this regard, because this 

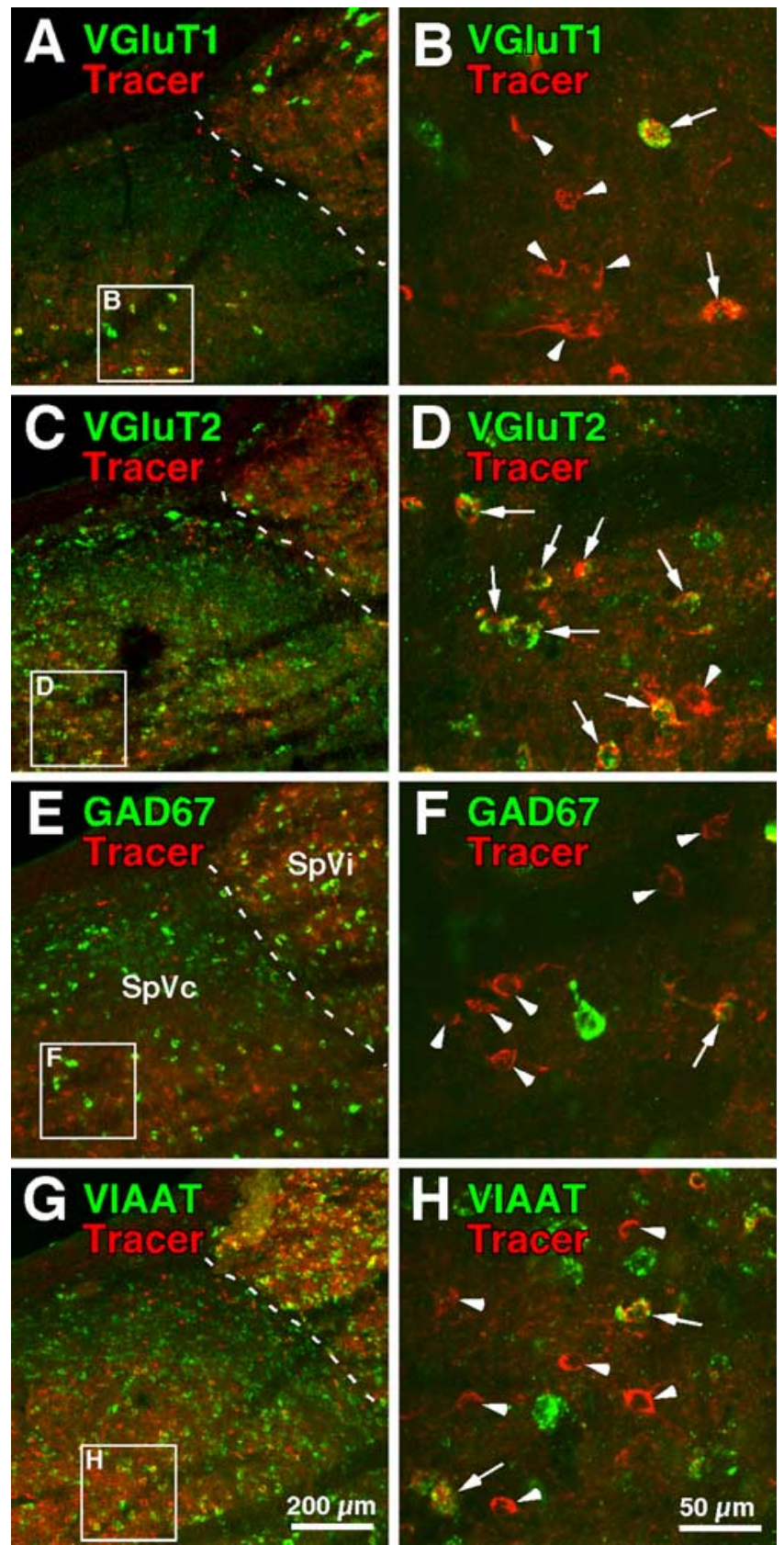

Figure 4. Expression of glutamate- and GABA-related specific transcripts in caudalis cells retrogradely labeled after (TB injection in the PrV. $\boldsymbol{A}-\boldsymbol{D}$ provide representative examples of singly labeled (arrowheads) or doubly labeled (arrows) neurons. Dotted lines indicate the border between the SpVi and SpVc. $\boldsymbol{E}-\boldsymbol{H}$, Framed areas in the SpVc are magnified in the corresponding right-hand panels.

vesicular transporter colocalizes in both GABAergic and glycinergic synaptic terminals (Dumoulin et al., 1999; Wojcik et al., 2006). Thus, the high proportion of PrV-projecting SpVic neurons that express VIAAT (86\%) provides compelling evidence for a strong intersubnuclear inhibitory control on synaptic transmission in the PrV. This conclusion is further supported by the near complete elimination of surround-whisker inhibition in the PrV in SpVi-lesioned rats. These results are also supported by the immunohistochemical study by Avendaño et al. (2005), who found the densest concentration of $\mathrm{GABA}$ and glycine immunoreactive cells in the $\mathrm{SpVc}$ and $\mathrm{SpVi}$, whereas the PrV contained the least. Among the PrV cells that express GABA-related transcripts, many more express VIAAT than GAD67, which suggests that local inhibitory transactions within the $\operatorname{PrV}$ are principally mediated by glycine, whereas both glycine and GABA mediate intersubnuclear inhibition. Yet, the actual organization of inhibitory connections in the trigeminal nuclei likely reaches a higher degree of complexity, for one cannot exclude the possibility that different classes of inhibitory neurons in the SpVi and SpVc use either glycine or GABA and establish synaptic contacts with different types of projection and local circuit cells.

The possibility that intersubnuclear projections might inhibit sensory transmission in the lemniscal pathway has already been anticipated by Haring et al. (1990), who tested for the existence of intersubnuclear GABAergic projections to the $\operatorname{PrV}$. However, for reasons that still remain unexplained, and possibly relates to a low GABA content or a low sensitivity of the immunolabeling technique, none of the retrogradely labeled cells in the SpVi and $\mathrm{SpVc}$ were found immunoreactive for GAD or GABA. The present results, however, leave little doubt about the existence of these inhibitory connections which were directly demonstrated by a variety of approaches that include electrophysiology and immunoelectron microscopy.

Surround whisker responses of $\operatorname{PrV}$ cells that give rise to the lemniscal pathway were shown previously to rely on intersubnuclear projections from the spinal trigeminal complex (Timofeeva et al., 2004). The respective contribution of the SpVi and $\mathrm{SpVc}$ to receptive field synthesis remained, however, undetermined. Our results reveal that the vast majority of glutamatergic intersubnuclear projections to the PrV arise from VgluT2expressing cells in the $\mathrm{SpVc}$, with a minor contribution from VGluT2-positive SpVi cells. Thus, the shrinkage of receptive field size in the PrV that results from an electrolytic lesion of the $\mathrm{SpVi}$ is likely attributable to the severing of the intersubnuclear axons that arise from the SpVc and travel through the SpVi. Excitatory projections from the $\mathrm{SpVc}$ may also be involved in the control of local inhibitory transactions by a direct action on GABAergic and glycinergic cells in the other subnuclei. Yet, for the moment, this is mostly conjecture that reflects our almost total ignorance of the intersubnuclear circuits.

\section{Central control of intersubnuclear-projecting neurons}

The wiring diagram in Figure 6 illustrates potential sources of higher-level feedback that can modulate the activity of intersubnuclear-projecting interpolaris cells. When retrograde tracers are injected into the $\mathrm{SpVi}$ of rodents, the vast majority of retrogradely labeled cells in the brain are found in the other trigeminal nuclei (Jacquin et al., 1990b), in the somatosensory cortical areas (Wise and Jones, 1977; Wise et al., 1979; Killackey et al., 1989), and in cholinergic neurons located in the pedunculopontine nucleus (Timofeeva et al., 2005). The actual impact of these inputs on the activity of intersubnuclear GABAergic cells is currently unknown, but available evidence suggest that they can exert a decisive influence on the way trigeminothalamic cells respond to vibrissal inputs (Woolston et al., 1983; Hallas and Jacquin, 1990; Jacquin et al., 1990a; Timofeeva et al., 2005). Thus, understanding how central inputs control the activity of intersubnuclear-projecting GABAergic cells should provide crucial information on the type of vibrissal messages that are conveyed to the cortex by the different ascending pathways of vibrissa information processing. 


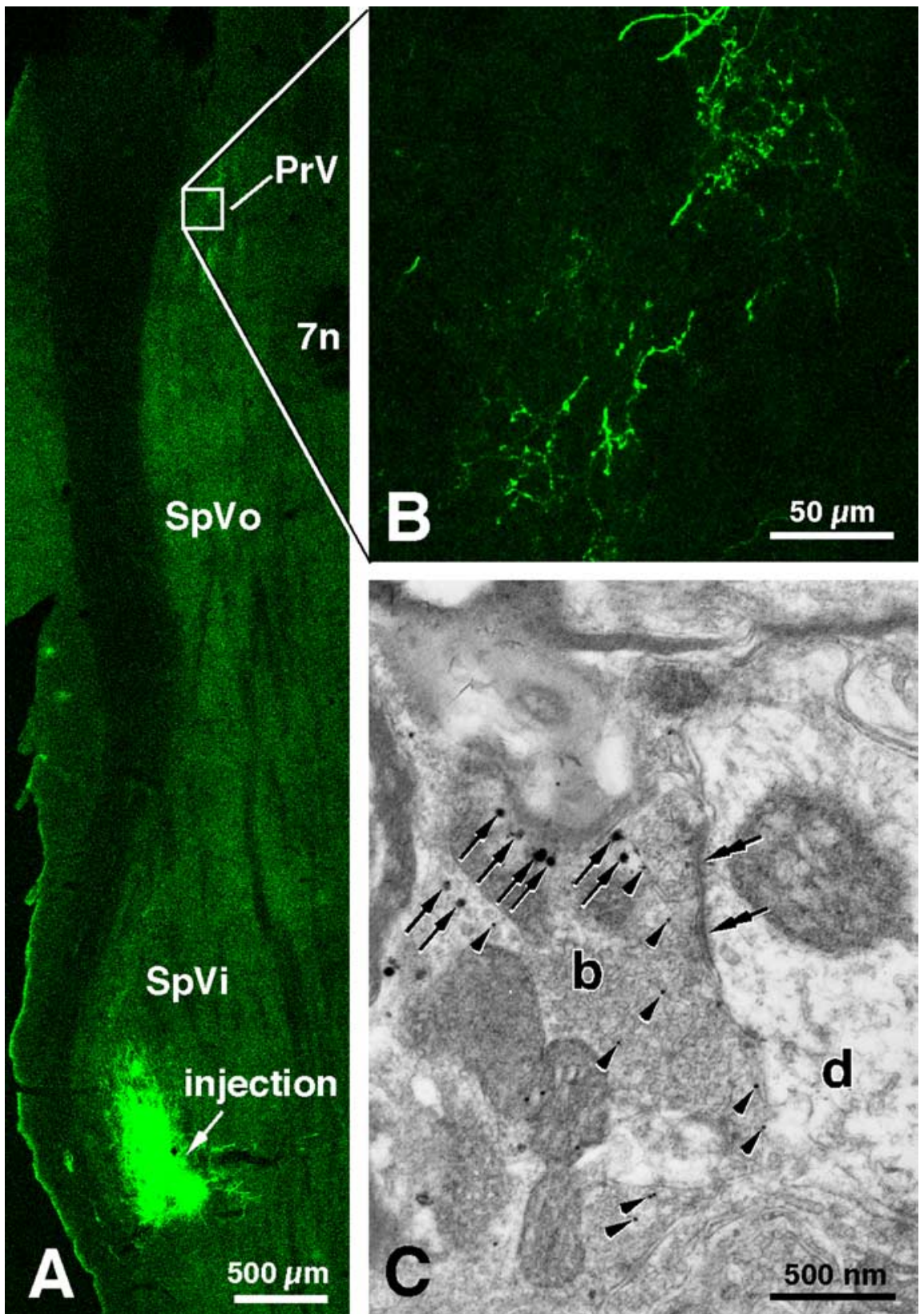

Figure 5. GABA immunoreactivity in terminals anterogradely labeled in the PrV after injection of GFP-expressing sindbis virus in the SpVi. Virus injection in the caudal sector of the SpVi $(\boldsymbol{A})$ led to the anterograde labeling of axons in the PrV $(\boldsymbol{B})$. The framed region in $\boldsymbol{A}$ is magnified in $\boldsymbol{B}$. $\boldsymbol{C}$, High-power electron micrograph of a $\mathrm{GFP}(+)$ terminal. Large black silver precipitates $(\boldsymbol{C}$, arrows) indicate the presence of GFP, and small black dots (arrowheads) show postembedding immunogold reactivity for GABA. The $\mathrm{GFP}(+)$ bouton (b) establishes symmetrical synaptic contacts (double-arrows) on a dendrite (d).

\section{Physiological significance}

Studies of primary vibrissa afferents agree on a number of general points. Trigeminal ganglion cells have single-whisker receptive field, exhibit sensitivity to the direction of movement, and differ from each other in being either rapidly or slowly adapting, or by encoding different ranges of whisker motion in terms of amplitude and velocity (Zucker and Welker, 1969; Gibson and Welker, 1983a,b; Lichtenstein et al., 1990; Shoykhet et al., 2000; Minnery and Simons, 2003; Stüttgen et al., 2006). Yet, the central projections of these cells are undistinguishable in the brainstem trigeminal complex, where individual afferents form ladder-like projection patterns consisting of several puffs of terminations distributed at regular interval $(150-200 \mu \mathrm{m})$ in each of the tri- geminal nuclei (Hayashi, 1980; Henderson and Jacquin, 1995). The discontinuous arbors from each of the fibers innervating a single whisker interdigitate to produce a rostrocaudally continuous column that is coextensive with the barrelette corresponding to the same vibrissa. Although we ignore what is mapped along the dimension of these columns, the distributed projection pattern of first-order afferents indicate that second-order neurons in each of the subnuclei of the trigeminal complex receive the same sensory messages, which implies that the parallel pathways that arise from these subnuclei do not relay inputs encoding different features of an object. They likely use the same information to inform the brain about whisker motion (proprioception), texture and shape, and object location in the whisking space, or again different pathways may be operative in different behavioral contexts [e.g., the exploratory and object recognition modes discussed by Curtis and Kleinfeld (2006)]. A context-dependent functional specialization implies mutually exclusive signaling activities, which may be the reason why intersubnuclear inhibitory connections are so prevalent in the brainstem.

One of the central issues in sensory physiology is understanding how an animal endowed with highly sensitive sensory organs with which it explores the environment can control the unceasing stream of sensory inputs it receives, and select those that are most relevant to an adaptive behavior. Clearly, there should exist multilevel gating mechanisms that filter out irrelevant sensory inputs. For example, when rats whisk to explore a new environment, they are likely little interested in object texture, no more than we are when we stretch out our arms to locate obstacles in a dark room. Processing texture information in this context appears behaviorally irrelevant, and there is no good reason to believe that this information must be conveyed to the cerebral cortex through the lemniscal pathway. Thus, sensory signals associated with different modes of tactual information processing (exploration, object recognition, whisking in air) may be differentially gated in brainstem trigeminal nuclei by inhibitory intersubnuclear projections.

\section{References}

Adams JC (1992) Biotin amplification of biotin and horseradish peroxidase signals in histochemical stains. J Histochem Cytochem 40:1457-1463.

Avendaño C, Machín R, Bermejo PE, Lagares A (2005) Neuron numbers in the sensory trigeminal nuclei of the rat: a GABA- and glycineimmunocytochemical and stereological analysis. J Comp Neurol 493:538-553

Bae YC, Ihn HJ, Park MJ, Otterson OP, Moritani M, Yoshida A, Yoshio S (2000) Identification of signal substances in synapses made between pri- 


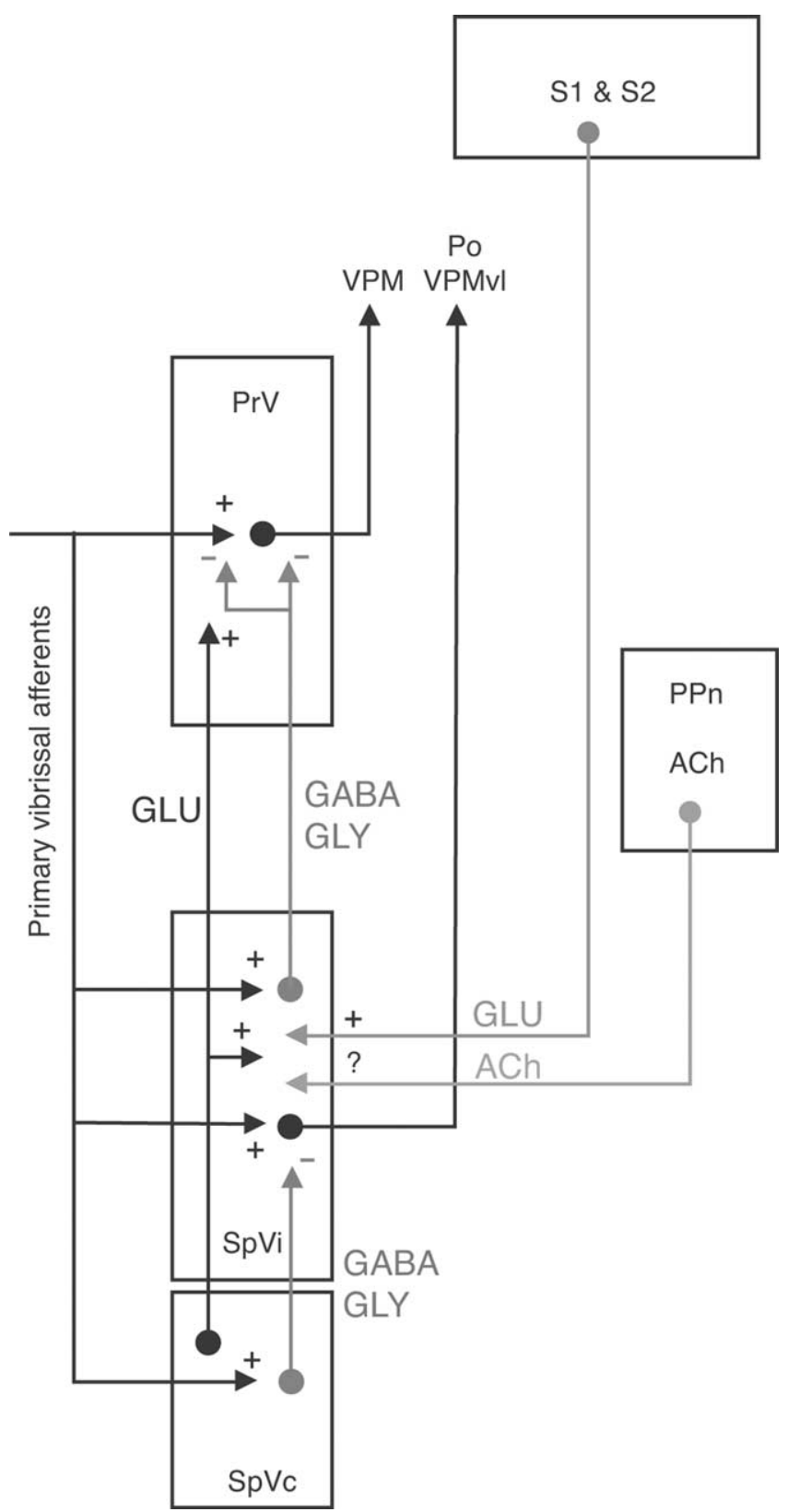

Figure 6. Circuit diagram of central projections that can potentially regulate the activity of intersubnuclear projecting cells in the SpVi. These projections arise from the other trigeminal subnuclei (principally the SpVc), the pedunculopontine nucleus (PPn), and the primary (S1) and second somatosensory areas (S2). Local intrasubnuclear connections have been omitted for simplicity. ACh, Acetylcholine; GLU, glutamate; GLY, glycine; Po, posterior group of the thalamus; VPM, ventral posterior medial nucleus; VPMvl, ventral lateral part of the VPM.

mary afferents and their associated axon terminals in the rat trigeminal sensory nuclei. J Comp Neurol 418:299-309.

Bae YC, Ihn HJ, Park MJ, Kim HN, Park SK, Bae JY, Lee HW, Kim KH, Yoshida A, Shigenaga Y (2005) The synaptic microcircuitry associated with primary afferent terminals in the interpolaris and caudalis trigeminal sensory complex. Brain Res 1060:118-125.

Curtis JC, Kleinfeld D (2006) Seeing what the mouse sees with its vibrissae: a matter of behavioral state. Neuron 50:524-526.

Dumoulin A, Rostaing P, Bedet C, Lévil S, Isambert MF, Henry JP, Triller A, Gasnier B (1999) Presence of the vesicular inhibitory amino acid transporter in GABAergic and glycinergic synaptic terminal boutons. J Cell Sci 112:811-823.

Friedberg MH, Lee SM, Ebner FF (1999) Modulation of receptive field properties of thalamic somatosensory neurons by the depth of anesthesia. J Neurophysiol 81:2243-2252.
Furuta T, Tomioka R, Taki K, Nakamura K, Tamamaki N, Kaneko T (2001) In vivo transduction of central neurons using recombinant Sindbis virus: Golgi-like labeling of dendrites and axons with membrane-targeted fluorescent proteins. J Histochem Cytochem 49:1497-1508.

Furuta T, Nakamura K, Deschênes M (2006) Angular tuning bias of vibrissa responsive cells in the paralemniscal pathway. J Neurosci 26:10548-10557.

Gibson JM, Welker WI (1983a) Quantitative studies of stimulus coding in first-order vibrissa afferents of rats 1 . Receptive field properties and threshold distributions. Somatosens Mot Res 1:51-67.

Gibson JM, Welker WI (1983b) Quantitative studies of stimulus coding in first-order vibrissa afferents of rats. 2. Adaptation and coding of stimulus parameters. Somatosens Mot Res 1:95-117.

Hallas BH, Jacquin MF (1990) Structure-function relationships in rat brain stem subnucleus interpolaris. IX. Inputs from subnucleus caudalis. J Neurophysiol 64:28-45.

Haring JH, Henderson TA, Jacquin MF (1990) Principalis- or parabrachial projecting spinal trigeminal neurons do not stain for GABA or GAD. Somatosens Mot Res 7:391-397.

Hayashi H (1980) Distributions of vibrissae afferent fibers collaterals in the trigeminal nuclei as revealed by intra-axonal injection of horseradish peroxidase. Brain Res 183:442-446.

Henderson TA, Jacquin MF (1995) What makes subcortical barrels? In: Cerebral cortex. The barrel cortex of rodents (Jones EG, Diamond IT, eds), pp 123-188. New York: Plenum.

Ide LS, Killackey HP (1985) Fine structural survey of the rat's brainstem sensory trigeminal complex. J Comp Neurol 235:145-168.

Ikeda M, Tanami T, Matsushita M (1984) Ascending and descending internuclear connections of the trigeminal sensory nuclei in the cat. A study with the retrograde and anterograde horseradish peroxidase technique. Neuroscience 12:1243-1260.

Jacquin MF, Golden J, Rhoades RW (1989a) Structure-function relationships in rat brainstem subnucleus interpolaris: III. Local circuit neurons. J Comp Neurol 282:24-44.

Jacquin MF, Barcia M, Rhoades RW (1989b) Structure-function relationships in rat brainstem subnucleus interpolaris: IV. Projection neurons. J Comp Neurol 282:45-62.

Jacquin MF, Wiegand MR, Renehan WE (1990a) Structure-function relationships in rat brain stem subnucleus interpolaris. VIII. Cortical inputs. J Neurophysiol 64:3-27.

Jacquin MF, Chiaia NL, Haring JH, Rhoades RW (1990b) Intersubnuclear connections within the rat trigeminal brainstem complex. Somatosens Mot Res 7:399-420.

Killackey HP, Koralek KA, Chiaia NL, Rhodes RW (1989) Laminar and areal differences in the origin of the subcortical projection neurons of the rat somatosensory cortex. J Comp Neurol 282:428-445.

Kleinfeld D, Ahissar E, Diamond ME (2006) Active sensation: insights from the rodent vibrissa sensorimotor system. Curr Opin Neurobiol 16:435-444.

Kwegyir-Afful EE, Bruno RM, Simons DJ, Keller A (2005) The role of thalamic inputs in surround receptive fields of barrel neurons. J Neurosci 25:5926-5934.

Lavallée P, Urbain N, Dufresne C, Bokor H, Acsady L, Deschênes M (2005) Feedforward inhibitory control of sensory information in higher-order thalamic nuclei. J Neurosci 25:7489-7498.

Liang F, Hatanaka Y, Saito H, Yamamori T, Hashikawa T (2000) Differential expression of gamma-aminobutyric acid type B receptor- $1 \mathrm{a}$ and $-1 \mathrm{~b}$ mRNA variants in GABA and non-GABAergic neurons of the rat brain. J Comp Neurol 416:475-495.

Lichtenstein SH, Carvell GE, Simons DJ (1990) Responses of rat trigeminal ganglion neurons to movements of vibrissae in different directions. Somatosens Mot Res 7:47-65.

Minnery BS, Simons DJ (2003) Response properties of whisker-associated trigeminothalamic neurons in rat nucleus principalis. J Neurophysiol 89:40-56.

Paxinos G, Watson C (1998) The rat brain in stereotaxic coordinates, Ed 4. London: Academic.

Salt TE (2002) Glutamate receptor functions in sensory relay in the thalamus. Philos Trans R Soc Lond B Biol Sci 357:1759-1766.

Shoykhet M, Doherty D, Simons DJ (2000) Coding of deflection velocity and amplitude by whisker primary afferent neurons: implications for higher level processing. Somatosens Mot Res 17:171-180. 
Somogyi P, Hodgson AJ, Chubb IW, Penke B, Erdei A (1985) Antisera to gamma-aminobutyric acid. II. Immunocytochemical application to the central nervous system. J Histochem Cytochem 33:240-248.

Stüttgen MC, Rüter J, Schwarz C (2006) Two psychophysical channels of whisker deflection in rats align with two neuronal classes of primary afferents. J Neurosci 26:7933-7941.

Timofeeva E, Lavallée P, Arsenault D, Deschênes M (2004) Synthesis of multiwhisker-receptive fields in subcortical stations of the vibrissa system. J Neurophysiol 91:1510-1515.

Timofeeva E, Dufresne C, Sik A, Zhang ZW, Deschênes M (2005) Cholinergic modulation of vibrissal receptive fields in trigeminal nuclei. J Neurosci 25:9135-9143.

Wise SP, Jones EG (1977) Cells of origin and terminal distribution of de- scending projections of the rat somatic sensory cortex. J Comp Neurol 175:129-158.

Wise SP, Murray EA, Coulter JD (1979) Somatotopic organization of corticospinal and corticotregiminal neurons in the rat. Neuroscience 4:65-78.

Wojcik SM, Katsurabayashi S, Guillemin I, Friauf E, Rosenmund C, Brose N, Rhee JS (2006) A shared vesicular carrier allows synaptic corelease of GABA and glycine. Neuron 50:575-587.

Woolston DC, La Londe JR, Gibson JM (1983) Corticofugal influences in the rat on responses of neurons in the trigeminal nucleus interpolaris to mechanical stimulation. Neurosci Lett 36:43-48.

Zucker E, Welker WI (1969) Coding of somatic sensory input by vibrissae in the rat's trigeminal ganglion. Brain Res 12:138-156. 